\title{
Fatty acid plasticity of black soldier fly (Hermetia Illucens) larvae reared on alternative feeding media: crude olive cake and processed animal protein
}

\author{
K. Starcevic ${ }^{1}$, L. Lozica ${ }^{2}$, A. Gavrilovic ${ }^{3}$, Z. Heruc ${ }^{4}$ and T. Masek ${ }^{5,6}$ \\ University of Zagreb, Faculty of Veterinary Medicine, \\ ${ }^{1}$ Department of Forensic and Judicial Veterinary Medicine, ${ }^{2}$ Department of Poultry Diseases with Clinic, ${ }^{5}$ Department of Animal \\ Nutrition and Dietetics, Zagreb, 10000, Croatia \\ ${ }^{3}$ Insektarij, Zagreb, 10000, Croatia \\ ${ }^{4}$ Agroproteinka, d.o.o, Zagreb, 10000, Croatia
}

KEY WORDS: crude olive cake, fatty acids, Hermetia illucens, insects, nutrition, processed animal protein

Received: 24 January 2019

Revised: 9 September 2019

Accepted: 12 December 2019

${ }^{6}$ Corresponding author:

e-mail: tomislav.masek@vef.hr

\begin{abstract}
The trial was performed to assess the effects of feeding media consisting of crude olive cake (COC) or processed animal protein (PAP) on the growth rate and the fatty acid composition of Hermetia illucens (black soldier fly) larvae (BSFL). The results showed a significant decrease in length and weight of larvae in the experimental groups reared on media containing $100 \%$ of PAP originating from poultry (PAP-P), mixed PAP (PAP-Mx) or COC compared to the control group fed on the basal diet (CON). The replacement of $50 \%$ of PAP with basal diet or wood shavings, significantly improved the length and weight of BSFL reared on both kinds of PAP; however not to the values obtained in the CON group. The addition of mineral and vitamin mixture into COC feeding significantly improved the growth of the BSFL, although it also did not attain the results of the basal diet. In comparison to the CON group, experimental groups containing $100 \%$ of PAP-P, PAP-Mx or COC were characterized by a decrease in the content of lauric acid and saturated fatty acids, and an increase in the content of oleic acid and monounsaturated fatty acids (MUFA). Especially high content of MUFA was observable in the COC group. The long-chain polyunsaturated fatty acid content was very low in all groups. In conclusion, with the usage of alternative feeding media, like PAP or COC, significant plasticity in the fatty acid profile of Hermetia illucens larvae could be achieved.
\end{abstract}

\section{Introduction}

The European Parliament adopted a resolution in 2011 on the European Union (EU) protein deficit: what is the solution for a long-standing problem? (2010/2111(INI)) (European Parliament, 2012). The resolution was based on the fact that more than $80 \%$ of the protein requirements of livestock reared in the EU is imported from non-EU countries. Since then, the rearing of insects as an alternative source of protein for feed has become an area of intensive scientific research.

The Hermetia illucens (L.) (black soldier fly, BSF) has emerged as one of the most interesting subjects of research, in the area of insects as alternative protein sources (Wang et al., 2017). As of 2018, insects, including BSF larvae (BSFL) are allowed as fish feed. Adult BSF are not considered pestiferous or invasive and they do not bite or sting (Sheppard et al., 2002; Čičková et al., 2015). Due to their 
behaviour and antimicrobial properties, they are not considered as biological vectors of specific pathogens, unlike most fly species (Furman et al., 1959; Sheppard et al., 2002; Choi et al., 2012).

The BSFL could be easily reared in a short period of time (2 to 3 weeks) using a huge diversity of feeding substrates, ranging from chicken feed to human or animal faeces (Sheppard, 1983; Green and Popa, 2012; Zheng et al., 2012; Lalander et al., 2013; Banks et al., 2014; Nguyen et al., 2015; Webster et al., 2016). The BSFL feed conversion ratio is very low and could be as low as 1.4 when they are fed a highprotein, high-fat diet, which makes it superior to most other insects (Oonincx et al., 2015). The survival rate of the BSFL is very high and does not depend significantly on the diet (Oonincx et al., 2015), whereas the survival rate of other insects may be greatly decreased when using specific diets (Starčević et al., 2017).

EU legislation on animal proteins in feed drastically changed after the outbreak of transmissible spongiform encephalopathies in the 1980s and 1990s. Nowadays, it is hard to expect that insects reared in feeding media containing human or animal faeces, or similar waste products, will be permitted to be used as animal feed in the EU. Therefore, it is essential to investigate how to maintain cheap and efficient production of BSFL by using permitted and safe byproducts.

Crude olive oil cake (COC) is a by-product of olive oil extraction. It is obtained by mechanical extraction and contains residual oil and stones. The chemical composition of COC is characterized by a high amount of crude fibre, which makes it adequate as feed only for animals that can digest large amounts of fibre (e.g., ruminants, rabbits) (Tortuero et al., 1989). Although COC can be used as animal feed, fertilizer or as an energy source (Molina-Alcaide and YáñezRuiz, 2008; Rodríguez et al., 2008), large quantities still remain accessible for use as insect feed in countries with high production of olive oil (Mediterranean basin). Processed animal protein (PAP) are animal proteins processed from any category 3 animal byproducts as defined by EU legislation. Since 2001 there has been a ban on the use of PAP in animal feed, but the possibility of using PAP has been constantly discussed at the EU level (EFSA, 2007; EFSA Panel on Biological Hazards, 2011; ESFA Panel on Biological Hazards et al., 2018).

Our trial was performed to assess the effects of feeding media consisting of COC or PAP on the growth rate and the fatty acid composition of BSFL, as well as the effects of the protein content in feeding media on the BSFL growth rate. Additionally, the possibilities of improving the growth of BSFL in experimental media containing PAP or COC by the addition of basal diet, wood shaving or mineralvitamin mixture was investigated.

\section{Material and methods}

\section{Rearing of insects and experimental design}

Hermetia illucens eggs and adults were obtained from the certified commercial breeder 'Insektarij' in Zagreb (Croatia). Black soldier fly eggs were incubated inside a closed container $(47 \mathrm{~cm}$ length $\times 32 \mathrm{~cm}$ width $\times 23 \mathrm{~cm}$ height) at $37.5 \pm 2{ }^{\circ} \mathrm{C}$ and $\sim 90 \%$ relative humidity. Strips of corrugated cardboard filled with the eggs were placed over $2 \mathrm{~kg}$ of basal diet (Table 1) mixed with water (80\%). The strips were not in contact with the substrate. After the eggs had hatched, the larvae were weighed $(1.0 \mathrm{~g})$, counted and transferred into non-transparent plastic boxes $(38 \mathrm{~cm}$ length $\times 28 \mathrm{~cm}$ width $\times 20 \mathrm{~cm}$

Table 1. The composition ${ }^{1}$ of the basal diet and by-products

\begin{tabular}{lcccc}
\hline Indices & $\begin{array}{c}\text { Basal } \\
\text { diet }\end{array}$ & PAP-P & PAP-Mx & COC \\
\hline Ingredients, g/kg & & & & \\
$\quad$ crude protein & 222 & 680 & 531 & 78.2 \\
crude fat & 30.4 & 140 & 130 & 124 \\
crude fibre & 46.5 & - & - & 381 \\
calcium & 10.4 & 52.4 & 116 & 73.2 \\
phosphorus & 5.0 & 29.7 & 58.9 & 8.7 \\
lysine & 12.2 & 32.1 & 30.3 & 0.3 \\
methionine & 6.5 & 9.3 & 85.7 & 0.4 \\
crude ash & 54.4 & 130 & 260 & 82.6
\end{tabular}

Fatty acid composition, $\%$ of total fatty acids

\begin{tabular}{lrrrc} 
C10:0 (capric) & 0.02 & 0.03 & 0.32 & 0.00 \\
C12:0 (lauric) & 0.91 & 0.16 & 0.49 & 0.00 \\
C14:0 (myristic) & 0.54 & 0.98 & 3.30 & 0.00 \\
C15:0 (pentadecanoic) & 0.02 & 0.15 & 0.40 & 0.00 \\
C16:0 (palmitic) & 16.97 & 30.85 & 29.18 & 13.64 \\
C16:1n7 (palmitoleic) & 0.69 & 5.32 & 2.38 & 0.92 \\
C17:0 (heptadecanoic) & 0.23 & 0.28 & 0.78 & 0.1 \\
C18:0 (stearic) & 4.39 & 10.29 & 18.72 & 1.84 \\
C18:1n9 (oleic) & 29.10 & 44.77 & 39.59 & 73.31 \\
C18:1n7 (trans-vaccenic) & 1.31 & 2.02 & 2.32 & 0.00 \\
C18:2n6 (linoleic) & 43.63 & 5.15 & 2.03 & 9.06 \\
C18:3n3 (linolenic) & 1.82 & 0.00 & 0.02 & 0.83 \\
C20:1n9 (cis-11-eicosenoic) & 0.37 & 0.00 & 0.43 & 0.00 \\
C20:5n3 (eicosapentaenoic, EPA) & 0.00 & 0.00 & 0.02 & 0.00 \\
C22:6n3 (docosahexaenoic, DHA) & 0.00 & 0.00 & 0.02 & 0.00 \\
\hline
\end{tabular}

${ }^{1}$ the samples were analysed according to the AOAC International (1995); PAP-P - processed animal protein originating from poultry; PAP-Mx - mixed processed animal protein; COC - crude olive cake 
height) with transparent lids, to prevent the larvae from escaping. The boxes contained basal diet or experimental feeding media. Groups were formed using four different feeding media: 1. basal diet (chicken feed; CON group); 2. processed animal protein of poultry origin (PAP-P); 3. processed animal protein of mixed origin (PAP-Mx); and 4. crude olive cake (COC). Additional groups were formed by mixing PAP feeding media with the basal diet (BD) or wood shavings (WS), and COC with mineral-vitamin mix (MV) (Table 2). Different protein levels $(22,25,30,40$ and $50 \%)$ were achieved by mixing the BD and egg white powder protein (Myprotein, The Hut Group, Cheshire, UK). Every group had 3 replicates. All feeding media were thoroughly mixed with water $(60 \%$ moisture) The thickness of feeding media was $5 \mathrm{~cm}$ in all groups and replicates. The experiments were conducted in temperature- and moisture-controlled environment (temperature $26 \pm 2{ }^{\circ} \mathrm{C}$; relative humidity $\sim 80 \%$ ).

Table 2. Experimental groups based on the used percentage of feeding media

\begin{tabular}{lrrrrrr}
\hline $\begin{array}{l}\text { Experimental } \\
\text { group }\end{array}$ & $\begin{array}{l}\text { Basal } \\
\text { diet }\end{array}$ & PAP-P & PAP-Mx & COC & MV & WS \\
\hline CON & 100 & 0 & 0 & 0 & 0 & 0 \\
COC & 0 & 0 & 0 & 100 & 0 & 0 \\
COC+MV & 0 & 0 & 0 & 95 & 5 & 0 \\
PAP-P & 0 & 100 & 0 & 0 & 0 & 0 \\
PAP-P+BD & 50 & 50 & 0 & 0 & 0 & 0 \\
PAP-P+WS & 0 & 50 & 0 & 0 & 0 & 50 \\
PAP-Mx & 0 & 0 & 100 & 0 & 0 & 0 \\
PAP-Mx+BD & 50 & 0 & 50 & 0 & 0 & 0 \\
PAP-Mx+WS & 0 & 0 & 50 & 0 & 0 & 50
\end{tabular}

PAP-P - processed animal protein originating from poultry; PAP-Mx - mixed processed animal protein; COC - crude olive cake; MV - mineral-vitamin mixture; WS - wood shavings

\section{Measurements}

After 14 days of rearing, the larvae were washed in water and individually measured. They were weighed using an electronic balance and their length was determined on photographs by measuring software (IC Measure, The Imaging Source Europe $\mathrm{GmbH}$, Bremen, Germany).

\section{Fatty acid analyses}

All chemicals were HPLC grade and were obtained from Sigma-Aldrich (Sigma-Aldrich, Steinheim, Germany). The lipids were extracted according to Folch et al. (1957) using a chloroform/ methanol mixture $(2: 1, \mathrm{v} / \mathrm{v})$. Total lipids were extracted from homogenized whole larvae with the addition of butylated hydroxytoluene as an antioxidant $(30 \mathrm{mg}$ per $100 \mathrm{ml})$ and nonadecanoic acid (C19:0) as an internal standard.

Transmethylation was performed using $2 \mathrm{M}$ $\mathrm{KOH}$ in methanol at room temperature. The analysis of fatty acid methyl esters was performed using a Shimadzu GC-MS QP2010 Ultra Gas Chromatograph Mass Spectrometer (Shimadzu, Kyoto, Japan) with a BPX70 capillary column $(0.25 \mathrm{~mm}$ internal diameter, $0.25 \mu \mathrm{m}$ film thickness, $30 \mathrm{~m}$ long; SGE, Austin, TX, USA) and helium as the carrier gas, as previously described (Starčević et al., 2017). The injector temperature was $250{ }^{\circ} \mathrm{C}$, the injection volume was $1 \mu$, the split ratio was 1:80 and linear velocity was $35 \mathrm{~cm} / \mathrm{s}$. The oven program was set as: initial temperature $40{ }^{\circ} \mathrm{C}$, held for $3 \mathrm{~min}$, then increased at the rate of $20^{\circ} \mathrm{C} / \mathrm{min}$ up to $130^{\circ} \mathrm{C}$, then increased at $1.5^{\circ} \mathrm{C} / \mathrm{min}$ up to $200^{\circ} \mathrm{C}$, and then increased at $45{ }^{\circ} \mathrm{C} / \mathrm{min}$ up to $250{ }^{\circ} \mathrm{C}$ and held for $10^{\circ} \mathrm{C}$. The results of fatty acid profile were expressed as the percentage of total fatty acids.

\section{Statistical analyses}

The data were analysed using one-way analysis of variance (ANOVA) followed by a Tukey's posthoc test in order to determine statistical differences between group means. Data were analysed using Statistica software ver. 12 (StatSoft, Tulsa, OK, USA). The statistical significance was set at $P<0.05$.

\section{Results}

The first part of the trial examined the influence of four different feeding media (basal diet $(\mathrm{CON})$, PAP-P, PAP-Mx and COC) in a $100 \%$ concentration on the BSFL length and weight. The results showed a significant decrease in length and weight (Figure $1 \mathrm{a}$ and $1 \mathrm{~b}$, respectively) in all experimental groups compared to the CON group. The complete absence of the early prepupae stage (reddish to brownish colour) in the PAP fed groups was observed (Figure 2).

Additional groups were introduced in the second part of the experiment by mixing the PAP feeding media with $50 \%$ of the BD or WS, while the COC feeding media was enriched with MV. The $50 \%$ of $\mathrm{BD}$, as well as WS, significantly improved the length and weight of BSFL reared in PAP-P (Figure 3) and PAP-Mx (Figure 4). The improvement of the BSFL weight was better in the PAP feeding media mixed with the BD compared to the WS.

To elucidate further the role of protein content in feeding media, the influence of protein contents, ranging from 22 to $50 \%$, on the BSFL length and weight was examined. The results showed 

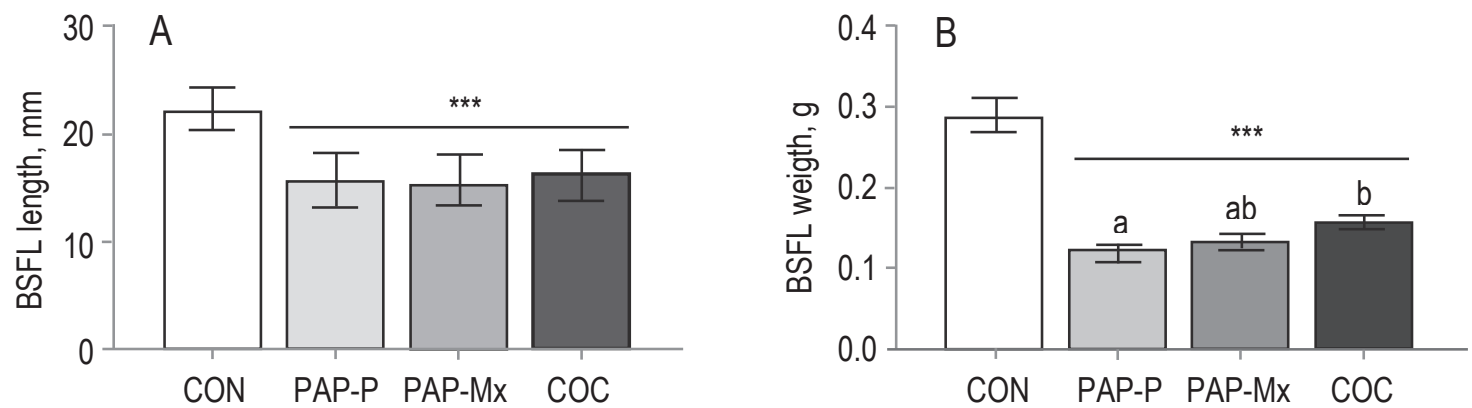

Figure 1. The influence of dietary treatment with processed animal protein (PAP) or crude olive cake (COC) on Hermetia illucens (black soldier fly) larvae (BSFL) length (A) and weight (B)

Groups: CON - control group fed basal diet (100\%); PAP-P - group fed on processed animal protein originating from poultry (100\%); PAP-Mx - group fed on mixed processed animal protein (100\%); COC - group fed on crude olive cake (100\%); ${ }^{* * *}-P<0.001$ for each experimental group vs CON one; $a-b-$ bars with different superscripts differ significantly

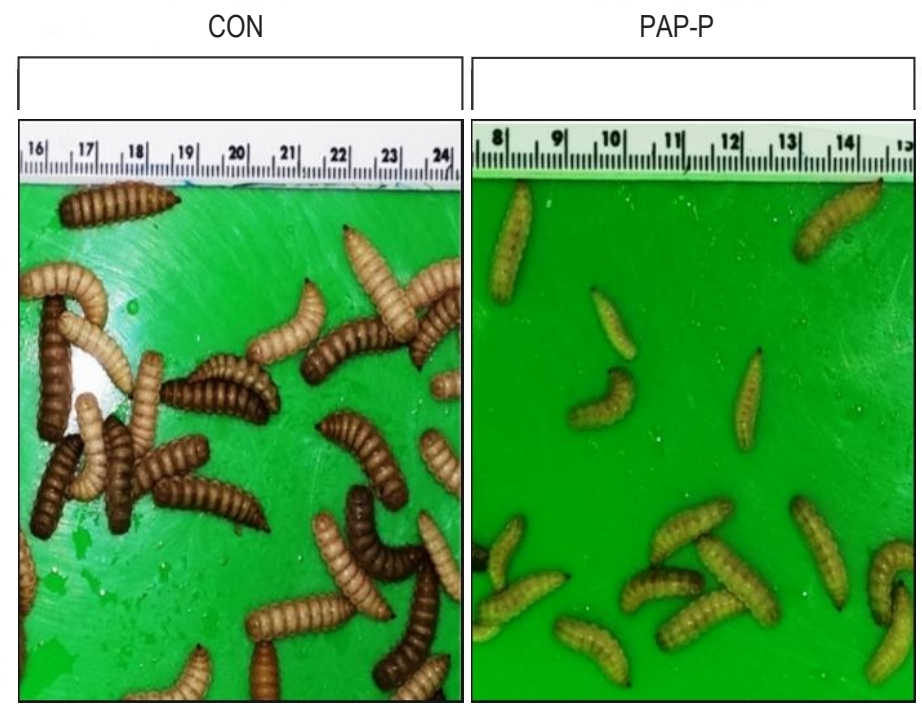

Figure 2. Hermetia illucens (black soldier fly) larvae (BSFL) development: BSFL fed basal diet (CON, $100 \%$ basal diet) developed normally (creamy white younger larvae and reddish to brownish mature larvae), while there were no mature larvae when processed animal protein originating from poultry (PAP-P, 100\%) was used as feeding media

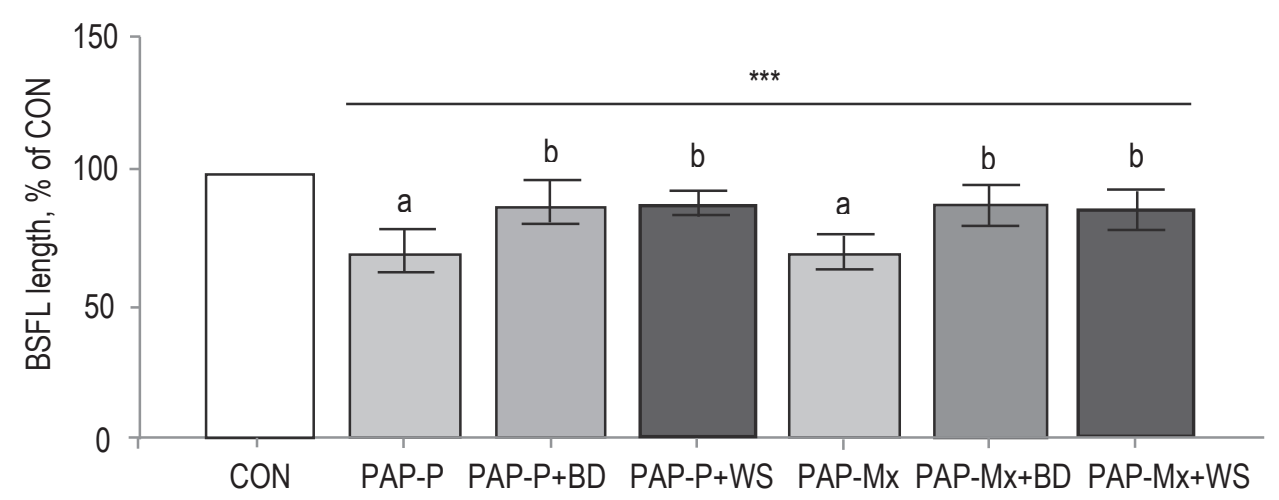

Figure 3. The influence of mixing the processed animal protein (PAP) with $50 \%$ of basal diet (BD) or wood shavings (WS) on the length of Hermetia illucens (black soldier fly) larvae (BSFL)

Groups: CON - control group fed on BD (100\%); PAP-P - group fed on processed animal protein originating from poultry (100\%); PAP-P+BD - group fed on PAP-P (50\%) mixed with BD (50\%); PAP-P+WS - group fed on PAP-P (50\%) mixed with WS (50\%); PAP-Mx - group fed on mixed processed animal protein (100\%); PAP-MX+BD - group fed on PAP-Mx (50\%) mixed with BD (50\%); PAP-Mx+WS - group fed on PAP-MX (50\%) mixed with WS (50\%); ${ }^{* * *}-P<0.001$ for each experimental group vs CON one; $a-b-$ bars with different superscripts differ significantly within the same dietary treatment (PAP-P and PAP-Mx, respectively) 


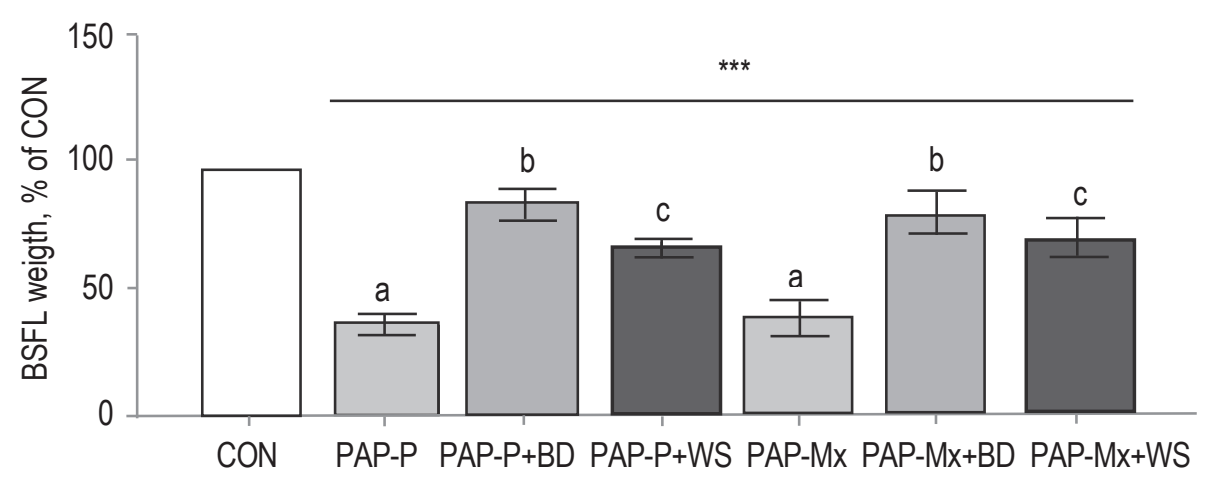

Figure 4. The influence of mixing the processed animal protein (PAP) with $50 \%$ of basal diet (BD) or wood shavings (WS) on the weight of Hermetia illucens (black soldier fly) larvae (BSFL)

Groups: CON - control group fed on BD (100\%); PAP-P - group fed on processed animal protein originating from poultry (100\%); PAP-P+BD - group fed on PAP-P (50\%) mixed with BD (50\%); PAP-P+WS - group fed on PAP-P (50\%) mixed with WS (50\%); PAP-Mx - group fed on mixed processed animal protein (100\%); PAP-MX+BD - group fed on PAP-Mx (50\%) mixed with BD (50\%); PAP-Mx+WS - group fed on PAP-MX (50\%) mixed with WS (50\%); ${ }^{* * *}-P<0.001$ for each experimental group vs CON one; a-c - bars with different superscripts differ significantly within the same dietary treatment (PAP-P and PAP-Mx, respectively)

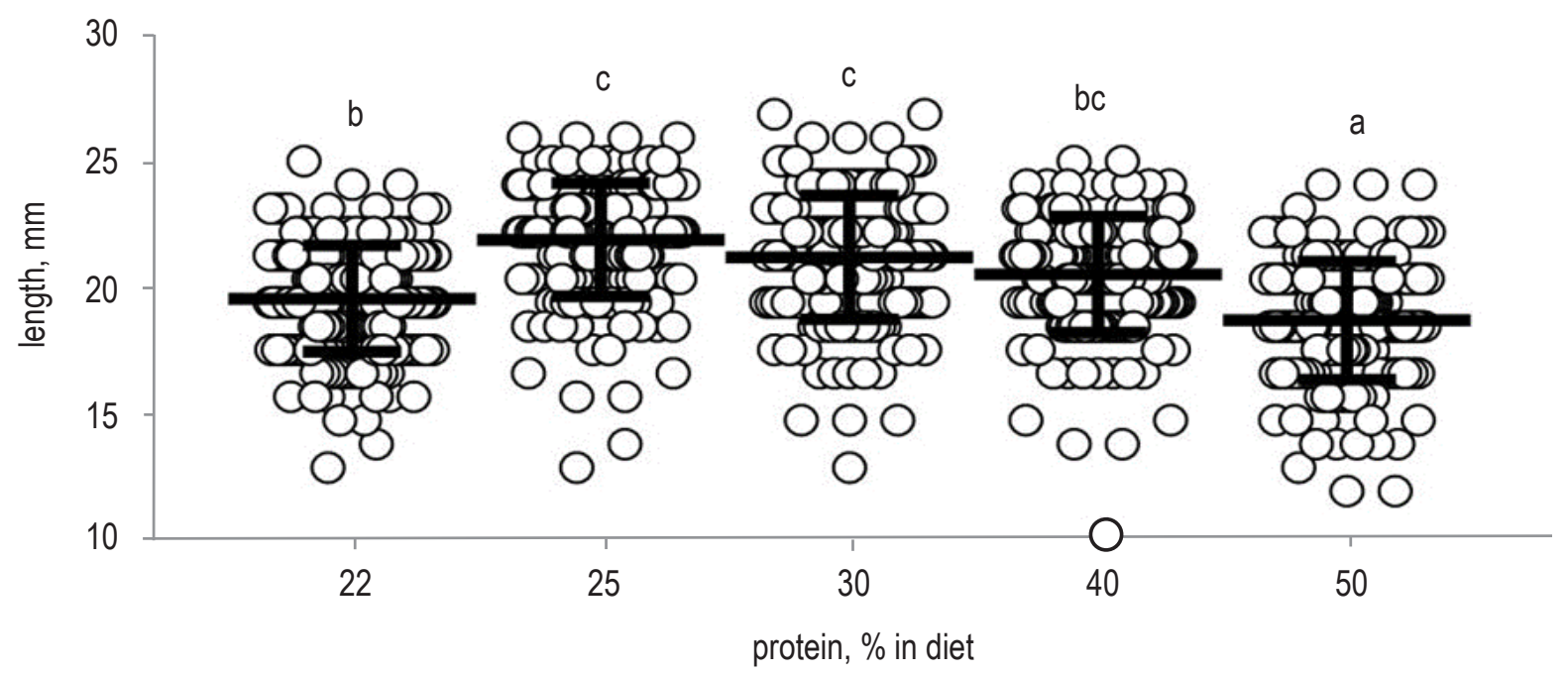

Figure 5. The influence of different levels of crude protein obtained by mixing basal diet with egg white powder protein on the length of Hermetia illucens (black soldier fly) larvae (BSFL); a-c - protein levels with different superscripts differ significantly at $P<0.05$

significant improvement in the growth of BSFL with 25 and $30 \%$ of protein, then no change with $40 \%$ of protein and then a significant decrease with $50 \%$ of protein in the feeding media in comparison to $22 \%$ protein level in feeding media (Figure 5).

With the COC feeding media supplemented with the mineral and vitamin mixture (MV), the growth of the BSFL significantly improved in comparison with COC feeding media, although it did not attain the results of the CON group (Figure 6).

The fatty acid profile of the experimental BSFL is presented in Table 3. In comparison to the CON group, experimental groups were characterized by a decrease in the content of lauric acid and saturated fatty acids (SFA), and an increase in the content of oleic acid and monounsaturated fatty acids (MUFA).
Especially high content of MUFA was observable in the COC group. An additional characteristic of the PAP groups was an increase in the palmitoleic acid and small amounts of EPA, which was not detectable in other groups. The polyunsaturated fatty acid (PUFA) content was very low in all groups, with the lowest value in the PAP-P group. Between the PAP groups, there was a significant difference in linoleic acid content, with almost 4-fold lower values in the PAP-Mx compared to the PAP-P group.

The plasticity of the BSFL fatty acid profile under the influence of different feeding media is assessed in Figure 7. It is observable that the highest plasticity could be seen for lauric acid (11-43\%) and oleic acid (11-54\%), followed by linoleic and linolenic acids. 

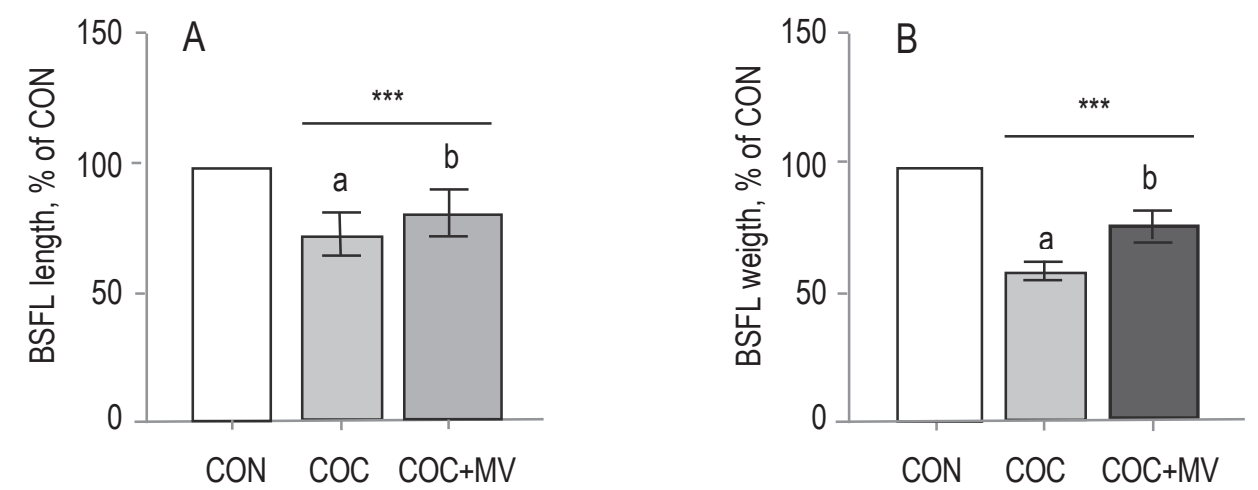

Figure 6. The effect of the crude olive cake (COC) alone or supplemented with a mineral and vitamin mixture (MV) on Hermetia illucens (black soldier fly) larvae (BSFL) length (A) and weight (B)

Groups: CON - control group fed on BD (100\%); COC - group fed on crude olive cake (100\%); COC+MV - group fed on COC (95\%) mixed with MV $(5 \%)$; ${ }^{* *}-P<0.001$ for each experimental group vs CON one; $a-b-$ bars with different superscripts differ significantly within the same dietary treatment $(\mathrm{COC})$

Table 3. The influence of oil addition on the fatty acid profile of Hermetia illucens larvae

\begin{tabular}{|c|c|c|c|c|}
\hline Fatty acids & CON & PAP-P & PAP-Mx & $\mathrm{COC}$ \\
\hline C10:0 (capric) & $0.59 \pm 0.05$ & $0.24 \pm 0.03^{\star \star *}$ & $0.29 \pm 0.04^{* * *}$ & nd \\
\hline C12:0 (lauric) & $36.5 \pm 1.75$ & $14.17 \pm 1.31^{* * *}$ & $17.4 \pm 0.65^{\star * *}$ & $11.85 \pm 1.56^{\star \star *}$ \\
\hline C14:0 (myristic) & $8.08 \pm 0.26$ & $3.66 \pm 0.23^{\star \star *}$ & $5.16 \pm 0.11^{* \star *}$ & $2.09 \pm 0.08^{\star * *}$ \\
\hline C16:0 (palmitic) & $18.0 \pm 0.79$ & $19.0 \pm 0.49$ & $18.0 \pm 0.41$ & $12.69 \pm 0.34^{* * *}$ \\
\hline C16:1n7 (palmitoleic) & $1.44 \pm 0.42$ & $6.77 \pm 0.22^{* * *}$ & $8.38 \pm 0.37^{* * *}$ & $1.26 \pm 0.05$ \\
\hline C18:0 (stearic) & $2.90 \pm 0.34$ & $4.35 \pm 0.02^{* *}$ & $4.48 \pm 0.29^{* *}$ & $1.40 \pm 0.01$ \\
\hline C18:1n9 (oleic) & $14.7 \pm 0.86$ & $31.5 \pm 0.34^{* * *}$ & $40.1 \pm 0.71^{* * *}$ & $54.12 \pm 1.05^{* * *}$ \\
\hline C18:1n7 (trans-vaccenic) & $0.52 \pm 0.17$ & $0.88 \pm 0.03^{*}$ & $0.93 \pm 0.06^{* *}$ & $0.82 \pm 0.10^{*}$ \\
\hline C18:2n6 (linoleic) & $16.3 \pm 1.74$ & $18.6 \pm 0.68^{* *}$ & $4.80 \pm 0.61^{\star * *}$ & $12.29 \pm 0.05^{*}$ \\
\hline C18:3n3 (linolenic) & $0.84 \pm 0.08$ & $0.60 \pm 0.01^{* *}$ & $0.23 \pm 0.06^{\star * *}$ & $0.44 \pm 0.03^{\star *}$ \\
\hline C20:1n9 (cis-11-eicosenoic) & nd & nd & nd & nd \\
\hline C20:5n3 (eicosapentaenoic, EPA) & nd & $0.06 \pm 0.00^{* * *}$ & $0.07 \pm 0.02^{\star * *}$ & nd \\
\hline C22:6n3 (docosahexaenoic, DHA) & nd & nd & nd & nd \\
\hline n6 & $16.3 \pm 1.74$ & $18.6 \pm 0.68^{* *}$ & $4.80 \pm 0.61^{* * *}$ & $12.2 \pm 0.05^{\star}$ \\
\hline n3 & $0.84 \pm 0.08$ & $0.66 \pm 0.02^{*}$ & $0.33 \pm 0.09^{* * *}$ & $0.44 \pm 0.03^{* *}$ \\
\hline n6/n3 & $19.4 \pm 0.95$ & $28.2 \pm 1.47^{\star \star}$ & $15.12 \pm 3.04$ & $28.58 \pm 1.75^{\star \star}$ \\
\hline MUFA & $16.7 \pm 0.68$ & $39.2 \pm 0.55^{\star \star \star}$ & $49.4 \pm 1.07^{\star \star *}$ & $59.14 \pm 1.19^{* \star *}$ \\
\hline PUFA & $17.1 \pm 1.81$ & $19.2 \pm 0.67^{* *}$ & $5.13 \pm 0.66^{* * *}$ & $12.73 \pm 0.08^{* *}$ \\
\hline SFA & $66.1 \pm 2.04$ & $41.5 \pm 1.06^{* \star *}$ & $45.4 \pm 0.91^{* * *}$ & $28.11 \pm 1.26^{* * *}$ \\
\hline
\end{tabular}

CON - control group fed basal diet (100\%); PAP-P - group fed on processed animal protein originating from poultry (100\%); PAP-Mx - group fed on mixed processed animal protein (100\%); COC - group fed on crude olive cake (100\%); nd - not determined (below quantification level); MUFA - monounsaturated fatty acids; PUFA - polyunsaturated fatty acids; SFA - saturated fatty acids; ${ }^{* * *}-P<0.001,{ }^{* *}-P<0.01$ and ${ }^{*}-P<0.05$ for each experimental group vs CON

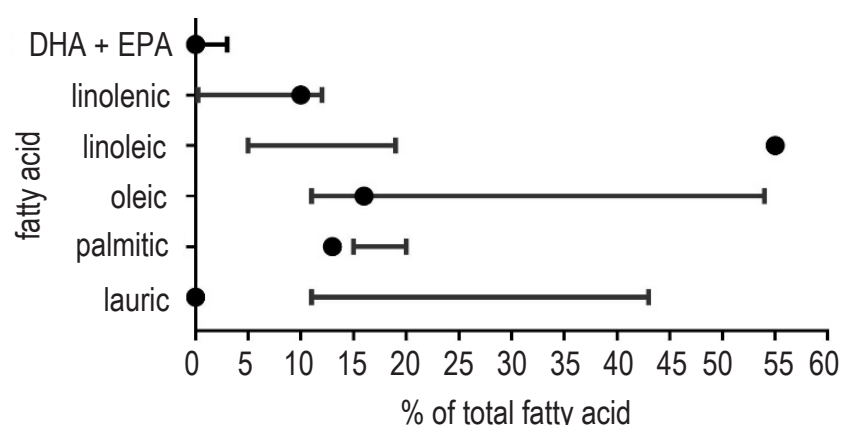

Figure 7. The plasticity of the fatty acid profile of Hermetia illucens (black soldier fly) larvae (BSFL) reared on different feeding media. The minimum and maximum range presented in the graph is composed from data including feeding media with processed animal protein originating from poultry (PAP-P), mixed processed animal protein (PAP-Mx), crude olive cake (COC) as well as $5 \%$ linseed oil, fish oil and coconut oil from our unpublished data. The average fatty acid profile of soybean meal $(\bullet)$ is included in the graph 


\section{Discussion}

Different by-products are especially interesting as feed for production animals due to their much higher viability in comparison to the traditional animal feed (e.g., grains). One-third of the world's cereal production is used as livestock feed each year (Foley et al., 2011). With the increasing demand for meat, demand for animal feed is also growing. Additionally, livestock farming has a great impact on the environment (e.g., deforestation, soil erosion, water pollution, greenhouse gas emission) (van Huis, 2013). The acceptance of by-products as feed depends on the efficacy of conversion into body mass by the production animal (Oonincx et al., 2015), as well as on legal issues that may emerge in relation to some by-products (e.g., PAP). Over the last two decades, a substantial amount of scientific data has been obtained on rearing BSFL. Nevertheless, a large amount of data, especially on the influence of feeding media on the nutritional composition of BSFL, is still missing. That gap in knowledge is the result of the poorly understood metabolism of BSFL, as well as the lack of nutritional trials on the plasticity of BSFL chemical composition (Oonincx et al., 2015).

The first part of the present trial compared the growth rates of BSFL fed on chicken feed, which is usually used on commercial farms, with feeding media consisting completely of processed animal protein from poultry or of mixed origin or crude olive cake. The data showed a reduction in BSFL growth in all groups based on examined by-products compared to the control diet during the 14-day trial.

In the second part of the trial, we addressed the main problems visible in the previous trial. The probable cause of the decreased growth in the PAP media was the muddy texture of the PAP mixed with water. The texture prevented movement, which led to the escape of BSFL from the media. Additionally, the unfavourable composition of media (excess protein, low content of fermentable components) contributed to the growth decrease. After mixing the PAP feeding media with $50 \%$ of the basal diet, a significant improvement was observed, indicating that an imbalance in the composition of the feeding media caused a decrease in the BSFL growth. After mixing the PAP feeding media with wood shavings, a similar significant increase in growth was visible, indicating that improvement in the feeding media texture may influence BSFL growth. Nevertheless, the improvement in the growth was much higher after the addition of basal diet than after the addition of wood shavings, indicating that improvement in the texture is not an adequate strategy, without balancing the composition of the feeding media. To assess the possible negative influence of protein excess further, we tested the influence of different protein contents on the BSFL growth. The results showed that $50 \%$ of protein in the feeding media leads to decreased BSFL growth compared to $22 \%$ present in chicken feed, which shows that highprotein by-products could affect BSFL growth.

The feeding media consisting of COC had an appropriate texture for BSFL, therefore, the more important problem could be dietary imbalance, mainly high-fibre content and low content of some minerals. The high-fibre content in the BSFL feeding media lowered BSFL growth, survival and development time, although BSFL can degrade cellulose, hemicellulose and lignin (Rehman et al., 2017). After the addition of the mineral and vitamin mixture to the COC feeding media, we observed a significant improvement in BSFL growth. These data show that $\mathrm{COC}$ could be an interesting and viable feeding media for BSFL, and that its performance may be improved even more after balancing the mineral content.

After the initial production trial, we tested the fatty acid profile of BSFL reared in different media to address the plasticity of the fatty acid profile. The most evident change in all experimental groups was the substitution of lauric acid with oleic acid. The high increase in oleic acid content was the consequence of its high content in the experimental feeding media. There is scientific evidence showing that the substitution of SFA with oleic acid has beneficial health effects (Lopez-Huertas, 2010; Sales-Campos et al., 2013; Palomer et al., 2018). In contrast, the content of beneficial $n 3$ and $n 6$ polyunsaturated fatty acids (PUFA) was not improved in our trial by using the experimental feeding media. As a consequence, the $\mathrm{n} 6 / \mathrm{n} 3$ ratio was very high in all experimental groups, indicating that only the addition of oils containing a high amount of PUFA can significantly decrease the $n 6 / n 3$ ratio to desirable levels (unpublished data).

\section{Conclusions}

In conclusion, our results showed that crude olive cake (COC) and processed animal protein (PAP) after modifications could be interesting feeding substrates for the rearing of Hermetia illucens (black soldier fly) larvae (BSFL). By using these feeding media, high plasticity in the lipid profile of 
BSFL could be achieved with increased quantities of oleic and lauric acid. The fat composition of BSFL could add significant value to the BSFL utilization as the source of oils for different industries.

\section{Acknowledgements}

The authors are grateful to 'Insektarij' for providing us with BSF and Agroproteinkad.o.o. for providing us with processed animal protein. T.M. designed the study and performed GC-MS analyses. L.L. and A.G. performed the trial on insects. Z.H. performed feed analyses. T.M. wrote the manuscript with support from K.S and L.L. The authors declared no conflict of interest.

\section{References}

AOAC International, 1995. Official Methods of Analysis of AOAC International. $16^{\text {th }}$ Edition. Arlington, VA (USA)

Banks I.J., Gibson W.T., Cameron M.M., 2014. Growth rates of black soldier fly larvae fed on fresh human faeces and their implication for improving sanitation. Trop. Med. Int. Health 19, 14-22, https://doi.org/10.1111/tmi.12228

Choi W.-H., Yun J.-H., Chu J.-P., Chu K.-B., 2012. Antibacterial effect of extracts of Hermetia illucens (Diptera: Stratiomyidae) larvae against Gram-negative bacteria. Entomol. Res. 42, 219-226, https://doi.org/10.1111/j.1748-5967.2012.00465.x

Čičková H., Newton G.L., Lacy R.C., Kozánek M., 2015. The use of fly larvae for organic waste treatment. Waste Manag. 35, 68-80, https://doi.org/10.1016/j.wasman.2014.09.026

EFSA (European Food Safety Authority), 2007. Certain Aspects related to the Feeding of Animal Proteins to Farm Animals -Scientific Opinion of the Panel on Biological Hazards. EFSA J. 5, 576, https://doi.org/10.2903/j.efsa.2007.576

EFSA Panel on Biological Hazards (BIOHAZ), 2011. Scientific Opinion on the revision of the quantitative risk assessment (QRA) of the BSE risk posed by processed animal proteins (PAPs). EFSA J. 9, 1947, https://doi.org/10.2903/j.efsa.2011.1947

EFSA Panel on Biological Hazards (EFSA BIOHAZ Panel), Ricci A., Allende A. et al., 2018. Evaluation of the application for a new alternative processing method for animal by-products of Category 3 material (ChainCraft B.V.). EFSA J. 16, 5281, https://doi.org/10.2903/j.efsa.2018.5281

European Parliament, 2012. EU protein deficit P7_TA(2011)0084. European Parliament resolution of 8 March 2011 on the EU protein deficit: what solution for a long-standing problem? (2010/2111(INI)). Off. J. EU C 199 E, 58-64

Folch J., Lees M., Sloane Stanley G.H., 1957. A simple method for the isolation and purification of total lipides from animal tissues. J. Biol. Chem. 226, 497-509

Foley J.A., Ramankutty N., Brauman K.A. et al., 2011. Solutions for a cultivated planet. Nature 478, 337-342, https://doi. org/10.1038/nature10452

Furman D.P., Young R.D., Catts P.E., 1959. Hermetia illucens (Linnaeus) as a factor in the natural control of Musca domestica Linnaeus. J. Econ. Entomol. 52, 917-921, https:// doi.org/10.1093/jee/52.5.917
Green T.R., Popa R., 2012. Enhanced ammonia content in compost leachate processed by black soldier fly larvae. Appl. Biochem. Biotechnol. 166, 1381-1387, https://doi.org/10.1007/s12010011-9530-6

Lalander C., Diener S., Magri M.E., Zurbrügg C., Lindström A., Vinnerås B., 2013. Faecal sludge management with the larvae of the black soldier fly (Hermetia illucens) - From a hygiene aspect. Sci. Total Environ. 458-460, 312-318, https://doi.org/10.1016/j.scitotenv.2013.04.033

Lopez-Huertas E., 2010. Health effects of oleic acid and long chain omega-3 fatty acids (EPA and DHA) enriched milks. A review of intervention studies. Pharmacol. Res. 61, 200-207, https:// doi.org/10.1016/j.phrs.2009.10.007

Molina-Alcaide E., Yáñez-Ruiz D.R., 2008. Potential use of olive byproducts in ruminant feeding: A review. Anim. Feed Sci. Technol. 147, 247-264, https://doi.org/10.1016/j.anifeedsci.2007.09.021

Nguyen T.T.X., Tomberlin J.K., Vanlaerhoven S., 2015. Ability of black soldier fly (Diptera: Stratiomyidae) larvae to recycle food waste. Environ. Entomol. 44, 406-410, https://doi. org/10.1093/ee/nvv002

Oonincx D.G.A.B., van Broekhoven S., van Huis A., van Loon J.J.A., 2015. Feed conversion, survival and development, and composition of four insect species on diets composed of food byproducts. PLoS ONE 10, e0144601, https://doi.org/10.1371/ journal.pone.0144601

Palomer X., Pizarro-Delgado J., Barroso E., Vázquez-Carrera M., 2018. Palmitic and oleic acid: the yin and yang of fatty acids in type 2 diabetes mellitus. Trends Endocrinol. Metab. 29, 178-190, https://doi.org/10.1016/j.tem.2017.11.009

Rehman K.u., Cai M., Xiao X., Zheng L., Wang H., Soomro A.A., Zhou Y., Li W., Yu Z., Zhang J., 2017. Cellulose decomposition and larval biomass production from the co-digestion of dairy manure and chicken manure by mini-livestock (Hermetia illucens L.). J. Environ. Manag. 196, 458-465, https://doi. org/10.1016/j.jenvman.2017.03.047

Rodríguez G., Lama A., Rodríguez R., Jiménez A., Guillén R., Fernández-Bolaños J., 2008. Olive stone an attractive source of bioactive and valuable compounds. Biores. Technol. 99, 5261-5269, https://doi.org/10.1016/j.biortech.2007.11.027

Sales-Campos H., Souza P.R., Peghini B.C., da Silva J.S., Cardoso C.R., 2013. An overview of the modulatory effects of oleic acid in health and disease. Mini Rev. Med. Chem. 13, 201-210

Sheppard C., 1983. House fly and lesser fly control utilizing the black soldier fly in manure management systems for caged laying hens. Environ. Entomol. 12, 1439-1442, https://doi. org/10.1093/ee/12.5.1439

Sheppard D.C., Tomberlin J.K., Joyce J.A., Kiser B.C., Sumner S.M., 2002. Rearing methods for the black soldier fly (Diptera: Stratiomyidae). J. Med. Entomol. 39, 695-698, https://doi. org/10.1603/0022-2585-39.4.695

Starčević K., Gavrilović A., Gottstein Ž., Mašek T., 2017. Influence of substitution of sunflower oil by different oils on the growth, survival rate and fatty acid composition of Jamaican field cricket (Gryllus assimilis). Anim. Feed Sci. Technol. 228, 66-71, https:// doi.org/10.1016/j.anifeedsci.2017.04.007

Tortuero F., Riopérez J., Rodríguez M.L., 1989. Nutritional value for rabbits of olive pulp and the effects on their visceral organs. Anim. Feed Sci. Technol. 25, 79-87, https://doi. org/10.1016/0377-8401(89)90109-0

van Huis A., 2013. Potential of insects as food and feed in assuring food security. Ann. Rev. Entomol. 58, 563-583, 10.1146/annurevento-120811-153704 
Wang Y.-S., Shelomi M., 2017. Review of black soldier fly (Hermetia illucens) as animal feed and human food. Foods 6, 91, https:// doi.org/10.3390/foods6100091

Webster C.D., Rawles S.D., Koch J.F., Thompson K.R., Kobayashi Y., Gannam A.L., Twibell R.G., Hyde N.M., 2016. Bio-Ag reutilization of distiller's dried grains with solubles (DDGS) as a substrate for black soldier fly larvae, Hermetia illucens, along with poultry by-product meal and soybean meal, as total replacement of fish meal in diets for Nile tilapia, Oreochromis niloticus. Aquac. Nutr. 22, 976-988, https://doi.org/10.1111/ anu. 12316
Zheng L., Hou Y., Li W., Yang S., Li Q., Yu Z., 2012. Biodiesel production from rice straw and restaurant waste employing black soldier fly assisted by microbes. Energy 47, 225-229, https://doi.org/10.1016/j.energy.2012.09.006 